\title{
META-ANAL YSIS: ENHANCING JUNIOR HIGH SCHOOL STUDENTS' HIGHER ORDER THINKING SKILLS THROUGH PROBLEM SOLVING LEARNING MODEL IN NATURAL SCIENCES-PHYSICS
}

\author{
Rian Sugianto ${ }^{1)}$, Niki Dian Permana $P^{* 2)}$, Diniya ${ }^{3)}$ \\ ${ }^{1,2,3)}$ Departement of Natural Sciences Education, State Islamic University of \\ Sultan Syarif Kasim Riau \\ e-mail: rian.sugianto@students.uin-suska.ac.id \\ ${ }^{*}$ niki.dian.permana@uin-suska.ac.id \\ diniya@uin-suska.ac.id
}

\begin{abstract}
This research aims to analyze the application of problem solving learning models to improve students' higher-order thinking skills in science-physics learning. This research was conducted using a meta-analysis method. The steps taken are collecting scientific articles from accredited national journals in Sinta 1 to Sinta 4 relating to research topics, grouping journal articles, and analyzing data obtained descriptively. Based on the results of the analysis it was concluded that the application of the problem solving learning model can improve student learning outcomes by an average of 55.45 in the medium category. For the group of articles with the dependent variable creative thinking skills, critical thinking skills, science process skills, problem solving skills and metacognition abilities, all of which are classified as higher order thinking skills, an average increase of 56.65 in the medium category.
\end{abstract}

Keywords: problem solving, higher order thinking skills, meta-analysis. 


\title{
META-ANALISIS: PENERAPAN MODEL PEMBELAJARAN PROBLEM SOL VING UNTUK MENINGKATKAN KETERAMPILAN BERPIKIR TINGKAT TINGGI SISWA SMP PADA PEMBELAJARAN IPA-FISIKA
}

\author{
Rian Sugianto ${ }^{1)}$, Niki Dian Permana $P^{* 2)}$, Diniya ${ }^{3)}$ \\ ${ }^{1,2,3)}$ Program Studi Tadris IPA, Universitas Islam Negeri Sultan Syarif Kasim Riau
}

\begin{abstract}
Abstrak
Penelitian ini bertujuan untuk menganalisis penerapan model pembelajaran problem solving untuk meningkatkan keterampilan berpikir tingkat tinggi siswa pada pembelajaran IPA-Fisika.. Penelitian ini dilakukan dengan menggunakan metode meta-analisis. Adapun langkah-langkah yang dilakukan adalah mengumpulkan artikel ilmiah dari jurnal nasional terakreditasi pada sinta 1 hingga sinta 4 yang berkaitan dengan topik penelitian, mengelompokkan artikel jurnal, dan menganalisis data-data yang diperoleh secara deskriptif. Berdasarkan hasil analisis diperoleh kesimpulan bahwa penerapan model pembelajaran problem solving dapat meningkatkan hasil belajar siswa dengan rata-rata 55,45 dengan kategori sedang. Untuk kelompok artikel dengan variabel terikat keterampilan berpikir kreatif, keterampilan berpikir kritis, keterampilan proses sains keterampilan pemecahan masalah dan kemampuan metakognisi yang kesemuanya itu tergolong sebagai keterampilan berpikir tingkat tinggi diperoleh rata-rata peningkatan sebesar 56,65 dengan kategori sedang.
\end{abstract}

Kata Kunci: problem solving, berpikir tingkat tinggi, meta-analisis.

\section{Pendahuluan}

Abad 21 adalah abad yang telah mengalami perubahan yang sangat mendasar, dimana era globalisasi memerlukan sumber daya manusia (SDM) yang mempunyai keterampilan hidup (life skills) dan mampu mengimbangi perkembangan ilmu pengetahuan dan teknologi. Menurut (Nori, 2019) life skills adalah keahlian atau keterampilan yang harus dimiliki oleh setiap individu untuk mengatasi setiap masalah yang dihadapi dalam menjalani kehidupan di masyarakat, kemudian secara proaktif dan kreatif mencari serta menemukan solusi untuk mengatasinya. Pada abad 21, diharapkan SDM akan mampu bersaing secara global, yaitu dalam hal keterampilan tingkat tinggi, berpikir kritis, logis, sistematis dan mampu bekerja sama dengan baik dan menguasai teknologi. SDM harus ditingkatkan melalui inovasi dalam pembelajaran yang disesuaikan dengan tuntutan pembelajaran abad 21 baik dalam pendidikan formal maupun informal.

Pendidikan adalah salah satu sarana yang digunakan untuk meningkatkan kualitas sumber daya manusia. Pendidikan itu sendiri menurut UU No. 20 Tahun 2003 tentang Sistem Pendidikan Nasional yakni usaha sadar dan terencana untuk mewujudkan suasana belajar dan proses pembelajaran agar siswa secara aktif mengembangkan potensi dirinya untuk memiliki kekuatan spiritual keagamaan, pengendalian diri, kepribadian, kecerdasan, akhlak mulia, serta keterampilan yang diperlukan dirinya, masyarakat, bangsa dan negara (Depdiknas, 2015). Banyak negara mengakui bahwa pendidikan sangat penting untuk kemajuan sebuah negara. (Rahmawati, 2013). Pendidikan di Indonesia disusun dalam kurikulum 2013.

Kurikulum 2013 memiliki tujuan mencakup empat kompetensi, yaitu (1) kompetensi sikap spiritual, (2) sikap sosial, (3) pengetahuan, dan (4) keterampilan. Kompetensi tersebut dicapai melalui proses pembelajaran intrakurikuler, kokurikuler, dan/atau ekstrakurikuler (Kemendikbud, 2016). Kemudian dalam proses pembelajaran harus tercipta komunikasi dua arah yaitu belajar dan mengajar (Kusumawati \& Konsim, 2013).

Menurut (Kusumawati \& Konsim, 2013) telah melakukan observasi dan wawancara 
kepada guru mata pelajaran fisika di SMPN 3 Batukliang, siswa kesulitan memahami materi fisika, apalagi menggunakan metode ceramah, jika siswa sulit memahami konsep-konsep fisika yang diajarkan akan berdampak pada rendahnya kualitas pendidikan. Seperti halnya hasil dari TIMMS (Trend of Internaitonal On Mathematic And Sains Study). Indonesia berada pada posisi 44 dari 49 negara tahun 2015 (Hadi, 2019). Berdasarkan hasil analisis menunjukkan bahwa rata-rata kemampuan fisika siswa Indonesia pada tiap aspek kognitif yaitu mengetahui, menerapkan berada dalam kategori tinggi, sedangkan aspek kognitif menalar (knowing, applying, and reasoning) masih rendah yang padahal aspek-aspek tersebut termasuk kedalam kategori kemampuan berpikir tingkat tinggi. Adapun Rata-rata kemampuan kognitif mengetahui (knowing) $(32,07)$ lebih tinggi dibandingkan dengan aspek kognitif menerapkan (applying) $(35,11)$ dan menalar (reasoning) $(22,23)$, padahal aspek mengetahui termasuk kedalam kemampuan berpikir tingkat rendah. Aspek yang mengalami penurunan tertinggi $4 \%$ adalah aspek menalar (reasoning) yang termasuk kedalam ciri berpikir tingkat tinggi taksonomi Bloom, sedangkan aspek mengetahui (knowing) dan mengaplikasikan (applying) masing-masing mengalami penurunan 3\% dan 1\% ini termasuk kedalam berpikir tingkat rendah (taksonomi Bloom). Data tersebut menunjukan bahwa berpikir tingkat tinggi siswa rendah. Banyak faktor yang mempengaruhi rendahnya berpikir tingkat tinggi siswa seperti halnya sikap ilmiah (Despaleri, 2015).

Berdasarkan hasil analisis penelitian oleh (Despaleri, 2015) rendahnya berpikir tingkat tinggi siswa, disebabkan oleh pembelajaran yang masih dilakukan secara konvensional di kelas, sehingga lebih berpusat pada guru (teacher-centred). Seharusnya pembelajaran berpusat pada siswa (student centered), dimana siswa mencoba menemukan dan membangun sendiri konsep materi yang diajarkan dengan bimbingan guru sebagai fasilitator sehingga orientasi pembelajaran cenderung mengacu pada teori kontruktivis. (Permana, 2018).

Melalui pembelajaran IPA terutama fisika, diharapkan siswa tidak hanya memiliki kemampuan menguasai konsep fisika saja (keterampilan berpikir dasar), tetapi juga memiliki kemampuan bernalar dalam berpikir analisis induktif dan deduktif (keterampilan berpikir kritis), serta memiliki kemampuan mengembangkan pengetahuan dan sikap percaya diri (keterampilan berpikir kreatif) dan tentunya menambah keimanannya kepada Tuhan Yang Maha Esa (Permana, 2018).

Para guru harus memiliki daya inovasi dan kreatifitas yang tinggi demi keberhasilan proses pembelajaran. Guru mengambil peran penting dalam perkembangan dan kemampuan peserta didik. Menurut Jonassen (2000), adapun kunci dalam proses pembelajaran adalah terdapatnya kegiatan pemecahan masalah, namun hal inilah yang menjadi kesulitan siswa. Siswa masih sulit menganalisis suatu masalah yang disajikan, sehingga akan kesulitan pula dalam mencari solusi. Solusi yang diberikan dapat dilakukan dengan mengumpulkan banyak referensi dan penjelasan-penjelasan. Adapun model pembelajaran problem solving dapat menjadi jalan keluar untuk mengatasi kesulitan siswa dalam menganalisis suatu masalah.

Model pembelajaran problem solving membuka pemikiran siswa untuk memonitor, dan mengoreksi strategi pembelajaran (Sweller, 1988). Model pembelajaran problem solving merupakan model pembelajaran yang mendorong siswa untuk memecahkan masalah (Meki, 2017). Siswa belajar memecahkan masalah maka akan menerapkan pengetahuan menimbulkan rasa ingin tahu, rasa kepuasan intelektual siswa akan timbul (Werdhiana \& Amiruddin, 2015).

Adapun sintaks problem solving antara lain sebagai berikut: a). memahami masalah, yakni mencari tahu apa yang diketahui dan apa yang ditanyakan, b). merencanakan pemecahannya, yakni menentukan cara menyelesaikan dan mencari hubungan antara data yang diketahui dan apa yang ditanyakan, dapatkah dipecahkan menjadi masalah yang lebih sederhana, c). menyelesaikan masalah sesuai rencana langkah kedua, yakni melaksanakan rencana dengan melaksanakan prosedur dalam mencari solusi, d). memeriksa kembali hasil yang diperoleh (looking back), yakni melihat kembali jawaban atau solusi yang telah ditemukan (Atqiya, 2016).

Mengenalkan model pembelajaran problem solving yang terdiri dari: a). mendefinisikan masalah, b). mendiagnosis masalah, c). merumuskan altenatif strategi, d). 
menentukan dan menerapkan strategi, e). mengevaluasi keberhasilan strategi pembelajaran (Firmansyah, 2009).

Model pembelajaran problem solving menerapkan pembelajaran berpusat pada siswa (student-centered). Proses-proses kreatif atau kreativitas ilmiah berpotensi melatih kemampuan berpikir, dan pembelajaran bisa dilaksanakan setelah siswa mencari informasi terlebih dahulu (I Wayana Gunanda \& Syahrizal Ayub, 2019). Dengan demikian Model pembelajaran problem solving dapat digunakan meningkatkan keterampilan berpikir tingkat tinggi.

Berpikir tingkat tinggi melibatkan beragam penerapan proses berpikir dalam situasi-situasi kompleks dan terdiri dari banyak variabel, yaitu berpikir kritis, logis, reflektif, metakognitif, dan berpikir kreatif. Dengan demikian keterampilan berpikir tingkat tinggi adalah keterampilan berpikir yang melibatkan proses berpikir kompleks seperti kritis, analitis, evaluatif, kreatif, dan reflektif dalam menyelesaikan masalah, dimana belum terdapat algoritma yang telah diajarkan untuk menyelesaikan masalah.

Berdasarkan hasil analisis, sintaks memahami masalah, merencanakan masalah, menentukan dan menerapkan strategi dan mengevaluasi hasil yang diperoleh yang ada pada model pembelajaran problem solving dapat meningkatkan kemampuan berpikir tingkat tinggi.

Keterampilan berpikir tingkat tinggi merupakan suatu keterampilan berpikir yang tidak hanya membutuhkan keterampilan mengingat, tetapi membutuhkan keterampilan lain yang lebih tinggi. Indikator untuk mengukur keterampilan berpikir tingkat tinggi meliputi keterampilan menganalisa (C4), mengevaluasi (C5), dan menciptakan (C6) (Rahmawati, 2018).

Menurut Anderson \& Krathwohl (2010) menganalisis melibatkan proses memecahmecah materi menjadi bagian-bagian kecil dan menentukan bagaimana hubungan antar bagian dan antara setiap bagian dan struktur keseluruhannya. Indikator dari menganalisis adalah membedakan, mengorganisasi, dan mengkontribusikan. Mengevaluasi merupakan mengambil keputusan berdasarkan kriteria dan atau standar. Indikator mengevaluasi adalah memeriksa dan mengkritik atau menilai. Mencipta merupakan memadukan bagian- bagian untuk membentuk sesuatu yang baru dan koheren atau untuk membuat suatu produk yang orisinil. Indikatornya adalah merumuskan, merencanakan dan memproduksi. Adapun indikator dari keterampilan berpikir tingkat tinggi adalah munculnya proses berpikir kritis, analitis, evaluatif, kreatif, dan reflektif (Ernawati, 2016).

\section{Bahan dan Metode}

Metode yang digunakan pada penelitian ini adalah meta-analisis. Langkah-langkah yang dilakukan dalam penelitian meta-analisis yaitu mengumpulkan artikel ilmiah dari jurnal nasional yang sudah terakreditasi pada sinta 1 hingga sinta 4 , yang terkait dengan tema yang akan diteliti. Dasar dari pengambilan artikel tersebut adalah disajikannya nilai rata-rata pretest dan posttest hasil penelitian pada artikel jurnal tersebut, yang nantinya akan dihitung peningkatan rata-rata keterampilan berpikir tingkat tinggi dari seluruh artikel yang dianalisis. Artikel jurnal diperoleh, lalu dikelompokkan yang relevan sesuai dengan tema penelitian yang dilakukan. Selanjutnya mencermati bagian-bagian penting dari setiap artikel berupa keterkaitan model problem solving dengan keterampilan berpikir tingkat tinggi siswa.

Artikel yang diperoleh dikelompokkan menjadi 2 jenis dalam pembahasannya, Pertama yaitu artikel yang variabel terikatnya keterampilan berpikir kreatif, keterampilan berpikir kritis, keterampilan proses sains, keterampilan pemecahan masalah dan kemampuan metakognisi yang kesemuanya itu tergolong sebagai keterampilan berpikir tingkat tinggi; Kedua, artikel yang variabel terikat pada judulnya adalah hasil belajar yang pembahasannya menjelaskan peningkatan hasil belajar pada indikator menganalisis (C4), mengevaluasi (C5) dan mencipta (C6).

Bentuk analisis data yang digunakan dalam penelitian ini adalah analisis deskriptif. Semua artikel jurnal yang diperoleh dianalisis peningkatan keterampilan berpikir tingkat tingginya dengan menggunakan skor gain yang dinormalisasi dengan rumus yang dikembangkan oleh Hake (1999).

$<g>=\frac{S_{\text {post }}-S_{\text {pre }}}{S_{\text {mideal }}-S_{\text {Pre }}}$ 
Keterangan:

$\mathrm{g}=$ skor rata-rata gain yang dinormalisasi

$\mathrm{S}_{\text {post }}=$ skor rata-rata tes akhir yang diperoleh siswa

$\mathrm{S}_{\text {pre }}=$ skor rata-rata tes awal yang diperoleh siswa

$\mathrm{S}_{m \text { ideal }}=$ skor maksimum ideal

Tabel 1. Kategori peningkatan keterampilan berpikir tingkat tinggi

\begin{tabular}{ccc}
\hline $\begin{array}{c}\text { Nilai } \\
<\mathrm{g}>\end{array}$ & $\begin{array}{c}\text { Persentase } \\
\text { Nilai }<\mathrm{g}>\end{array}$ & Kategori \\
\hline$<\mathrm{g}>\geq 0,7$ & $<\mathrm{g}>\geq 70$ & Tinggi \\
$0,3 \leq<\mathrm{g}><0,7$ & $30 \leq<\mathrm{g}><70$ & Sedang \\
$<\mathrm{g}><0,3$ & $<\mathrm{g}><30$ & Rendah \\
\hline
\end{tabular}

Kategori peningkatan gain yang dinormalisasi untuk menyatakan peningkatan keterampilan berpikir tingkat tinggi siswa disajikan pada Tabel 1.

\section{Hasil dan Pembahasan}

Hasil data penelitian yang dimasukkan dalam meta-analisis adalah data dari artikel yang dianalisis secara kuantitatif terkait dengan hasil belajar dan keterampilan berpikir tingkat tinggi sebagaimana yang disajikan pada Tabel 2 dan Tabel 3.

Tabel 2. Hasil analisis pengaruh penerapan model pembelajaran problem solving terhadap hasil belajar

\begin{tabular}{|c|c|c|c|c|c|c|c|c|}
\hline \multirow[b]{2}{*}{ No } & \multirow[b]{2}{*}{ Judul Penelitian } & \multirow[b]{2}{*}{ Peneliti } & \multirow[b]{2}{*}{ Tahun } & \multicolumn{4}{|c|}{ Hasil Belajar } & \multirow[b]{2}{*}{ Keterangan } \\
\hline & & & & Sebelum & Sesudah & Gain & $\begin{array}{l}\text { Gain } \\
(\%)\end{array}$ & \\
\hline 1 & $\begin{array}{l}\text { Efek Model Pembelajaran } \\
\text { Problem Solving dan } \\
\text { Motivasi terhadap Hasil } \\
\text { Belajar Fisika Siswa SMA }\end{array}$ & $\begin{array}{l}\text { Grace Dennys } \\
\text { Hutabarat dan } \\
\text { Sahyar }\end{array}$ & 2013 & 39,50 & 62,00 & 0,37 & 37,19 & Sedang \\
\hline 2 & $\begin{array}{l}\text { Pengaruh Penggunaan } \\
\text { Metode Problem Solving } \\
\text { Learning terhadap Hasil } \\
\text { Belajar Fisika Siswa Kelas } \\
\text { XII IPA MAN 1 Pesisir } \\
\text { Selatan. }\end{array}$ & $\begin{array}{l}\text { Septika Ulan } \\
\text { Meki }\end{array}$ & 2017 & 70,02 & 80,3 & 0,34 & 34,28 & Sedang \\
\hline 3 & $\begin{array}{l}\text { Peningkatan Hasil Belajar } \\
\text { IPA Fisika dengan } \\
\text { Menggunakan Model } \\
\text { Pembelajaran Problem } \\
\text { Solving pada Siswa Kelas } \\
\text { VII SMP Negeri } 18 \text { Palu }\end{array}$ & $\begin{array}{l}\text { I Komang } \\
\text { Werdhiana } \\
\text { dan H. } \\
\text { Amiruddin } \\
\text { hatibe }\end{array}$ & 2015 & 37,32 & 83,45 & 0,73 & 73,59 & Tinggi \\
\hline 4 & $\begin{array}{l}\text { Pengaruh Model } \\
\text { Pembelajaran Partisipatif } \\
\text { Menggunakan Metode } \\
\text { Pemecahan Masalah terhadap } \\
\text { Hasil Belajar Fisika Siswa } \\
\text { Kelas VIII SMPN } 3 \\
\text { Batukliang }\end{array}$ & $\begin{array}{l}\text { A. } \\
\text { Kusumawati, } \\
\text { Kosim, dan } \\
\text { Gunawan }\end{array}$ & 2013 & 33 & 54 & 0,31 & 31,34 & Sedang \\
\hline 5 & $\begin{array}{l}\text { Pengaruh Model } \\
\text { Pembelajaran Problem } \\
\text { Solving Terhadap Hasil } \\
\text { Belajar Fisika Siswa Kelas } \\
\text { VIII SMPN 5 Lingsar Tahun } \\
\text { Pelajaran 2012/2013 }\end{array}$ & Rahmawati & 2013 & 32 & 75 & 0,63 & 63,23 & Sedang \\
\hline 6 & $\begin{array}{l}\text { Pengaruh Pembelajaran } \\
\text { Model Problem Solving } \\
\text { Berorientasi Higher Order } \\
\text { Thinking Skills terhadap } \\
\text { Hasil Belajar }\end{array}$ & $\begin{array}{l}\text { Safri } \\
\text { Daryanti, } \\
\text { Indra Sakti, } \\
\text { Dedy } \\
\text { Hamdani } \\
\end{array}$ & 2019 & 22,95 & 82,55 & 0,77 & 77,35 & Tinggi \\
\hline & Rata-Rata & & & 39,13 & 72,88 & 0,55 & 55,45 & Sedang \\
\hline
\end{tabular}


Tabel 3. Analisis pengaruh model pembelajaran problem solving terhadap peningkatan keterampilan berpikir tingkat tinggi

\begin{tabular}{|c|c|c|c|c|c|c|c|c|}
\hline \multirow{2}{*}{ No } & \multirow{2}{*}{ Judul Penelitian } & \multirow{2}{*}{ Peneliti } & \multirow{2}{*}{ Tahun } & \multicolumn{4}{|c|}{$\begin{array}{c}\text { Peningkatan Keterampilan } \\
\text { Berpikir Tingkat Tinggi }\end{array}$} & \multirow{2}{*}{ Kategor } \\
\hline & & & & Sebelum & Sesudah & Gain & $\begin{array}{c}\text { Gain } \\
(\%)\end{array}$ & \\
\hline 1 & $\begin{array}{l}\text { Pengembangan Model } \\
\text { Pembelajaran Problem } \\
\text { Solving Berbasis Video } \\
\text { terhadap Metakognisi } \\
\text { Siswa. }\end{array}$ & $\begin{array}{l}\text { Mariati } \\
\text { Purnama } \\
\text { Simanjuntak }\end{array}$ & 2014 & 19,79 & 66,91 & 0,59 & 59 & Sedang \\
\hline 2 & $\begin{array}{l}\text { Pengembangan Model } \\
\text { Pembelajaran Fisika } \\
\text { Berbasis Problem Solving } \\
\text { untuk Meningkatkan } \\
\text { Kemampuan Metakognisi } \\
\text { Mahasiswa }\end{array}$ & P.S. Mariati & 2012 & 17,43 & 70,43 & 0,64 & 64,18 & Sedang \\
\hline 3 & $\begin{array}{l}\text { Pengaruh Model } \\
\text { pembelajaran Berbasis } \\
\text { Masalah Berbantuan Mobile } \\
\text { Pocket Book Fisika } \\
\text { terhadap Kemampuan } \\
\text { Pemecahan Masalah Peserta } \\
\text { Didik }\end{array}$ & $\begin{array}{l}\text { Rindayu } \\
\text { Noviatika, } \\
\text { Gunawan, dan } \\
\text { Joni Rokhmat }\end{array}$ & 2019 & 28,2 & 68,3 & 0,33 & 55,85 & Sedang \\
\hline 4 & $\begin{array}{l}\text { Pengaruh Pembelajaran } \\
\text { Model Problem Solving } \\
\text { Berorientasi Higher Order } \\
\text { Thinking Skills terhadap } \\
\text { Kemampuan Pemecahan } \\
\text { Masalah }\end{array}$ & $\begin{array}{l}\text { Safri } \\
\text { Daryanti, } \\
\text { Indra Sakti, } \\
\text { Dedy } \\
\text { Hamdani }\end{array}$ & 2019 & 31,45 & 75,53 & 0,44 & 44,08 & Sedang \\
\hline 5 & $\begin{array}{l}\text { Pengembangan LKPD } \\
\text { Fisika Berbasis Problem } \\
\text { Solving untuk } \\
\text { Meningkatkan } \\
\text { Keterampilan Proses Sains }\end{array}$ & $\begin{array}{l}\text { Mujib } \\
\text { Ubaidillah }\end{array}$ & 2016 & 71 & 86 & 0,48 & 48 & Sedang \\
\hline 6 & $\begin{array}{l}\text { Impementasi Lesson Study } \\
\text { Melalui Model } \\
\text { Pembelajaran Problem } \\
\text { Solving untuk } \\
\text { Meningkatkan Kemampuan } \\
\text { Berpikir Kreatif }\end{array}$ & $\begin{array}{l}\text { I Wayan } \\
\text { Gunada, } \\
\text { Syahrial } \\
\text { Ayub, dan } \\
\text { Kesipudin }\end{array}$ & 2019 & 69,28 & 74,68 & 0,63 & 63 & Sedang \\
\hline 7 & $\begin{array}{l}\text { Analisis Pengaruh Model } \\
\text { Pembelajaran Berbasis } \\
\text { Masalah dengan } \\
\text { Menggunakan Media Flash } \\
\text { dan Sikap Ilmiah terhadap } \\
\text { Kemampuan Berpikir } \\
\text { Tingkat Tinggi Fisika Siswa } \\
\text { SMA. }\end{array}$ & $\begin{array}{l}\text { Despaleri } \\
\text { Peranginangin } \\
\text { dan Sahyar }\end{array}$ & 2015 & 35,8 & 72,6 & 0,57 & 57,3 & Sedang \\
\hline 8 & $\begin{array}{l}\text { Pengembangan LKPD } \\
\text { Fisika Berbasis Problem } \\
\text { Solving untuk } \\
\text { Meningkatkan } \\
\text { Keterampilan Berpikir } \\
\text { Tingkat Tinggi } \\
\end{array}$ & $\begin{array}{l}\text { Mujib } \\
\text { Ubaidillah }\end{array}$ & 2016 & 64 & 82 & 0,49 & 49 & Sedang \\
\hline & Rata-Rata & & & 42,11 & 74,56 & 0,56 & 56,05 & Sedang \\
\hline
\end{tabular}

Tabel 2 menunjukkan bahwa penerapan model pembelajaran problem solving dapat meningkatkan hasil belajar siswa dengan ratarata peningkatan sebesar 55,45 dengan kategori sedang. Pada semua artikel tidak ditemukan penjelasan secara terperinci terkait dengan indikator hasil belajar menganalisis (C4), mengevaluasi (C5) dan mencipta (C6). 
Berdasarkan Tabel 3, artikel yang dianalisis merupakan artikel yang variabel terikatnya berupa keterampilan berpikir kreatif, kemampuan pemecahan masalah dan kemampuan metakognisi yang kesemuanya itu termasuk dalam kategori keterampilan berpikir tingkat tinggi. Berdasarkan data pada Tabel 3. terlihat bahwa rata-rata peningkatan keterampilan berpikir tingkat tinggi siswa akibat dari efek penerapan model pembelajaran problem solving adalah 56,05 dengan kategori sedang. Model pembelajaran problem solving memberikan pengaruh peningkatan paling tinggi pada kemampuan metakognisi sebesar 64,18 dengan kategori sedang.

Tingginya peningkatan kemampuan metakognisi karena pada pembelajaran problem solving, kemampuan metakognisi dapat dikontruksi saat siswa memecahkan permasalahan yang diperoleh saat proses pembelajaran.

Saat proses problem solving dilakukan, kesadaran kognisi siswa berkembang akibat adanya tuntutan, agar bertanya pada dirinya tentang seberapa paham dengan materi yang sedang dipelajari. Problem solving yang dilakukan mengarahkan siswa untuk mengetahui apa yang belum diketahuinya dan bagaimana cara menyelesaikan permasalahan yang dimulai dari tahapan merencanakan cara pemecahan masalah, membuat langkahlangkah pemecahan masalah, mengawasi proses pemecahan masalah hingga melakukan evaluasi terhadap keseluruhan proses yang telah dilakukan. Dengan demikian, kemampuan metakognisi dapat ditumbuh kembangkan dengan baik melalui penerapan pembelajaran problem solving. Garrett \& Mazzocco (2006) menyatakan bahwa metakognisi dapat dikembangkan dalam suatu lingkungan pembelajaran problem solving.

Arends (1997) menyatakan bahwa pada pembelajaran problem solving siswa dihadapkan pada permasalahan yang nyata sehingga diharapkan siswa dapat menyusun pengetahuannya sendiri, menumbuh kembangkan keterampilan tingkat tinggi dan inkuiri, memandirikan siswa, dan meningkatkan kepercayaan diri.

Belajar dengan menggunakan model problem solving pada hakekatnya adalah melatihkan siswa untuk belajar berpikir dan bernalar dengan cara mengaplikasikan pengetahuan-pengetahuan yang telah diperoleh sebelumnya untuk memecahkan permasalahan.

Hanson \& Wolfskill (2000) menyatakan bahwa problem solving melalui kerja tim bisa meningkatkan keterampilan siswa dalam berpikir kritis, aktif dalam mencari informasi, mengkonstruk pemahaman, dan keterampilan memberikan alasan tingkat tinggi sehingga pembelajaran problem solving memberikan peluang bagi siswa untuk mengalami proses pembelajaran yang lebih bermakna (meaningfull). Oleh karena itu, pembelajaran dengan problem solving dirancang sedemikian rupa untuk dapat mengaktifkan atau merangsang daya pikir siswa sehingga secara sadar dapat memecahkan masalah menggunakan kemampuan berpikirnya.

\section{Kesimpulan dan Saran}

Berdasarkan hasil analisis data dapat disimpulkan bahwa model pembelajaran problem solving dapat meningkatkan hasil belajar siswa dengan rata-rata skor 55,45 berkategoi sedang. Selain itu, untuk keterampilan berpikir kreatif, keterampilan berpikir kritis, keterampilan proses sains, keterampilan pemecahan masalah dan kemampuan metakognisi yang kesemuanya itu tergolong sebagai keterampilan berpikir tingkat tinggi.

Terjadi peningkatan dengan nilai rata-rata 56,05 dengan kategori sedang, meskipun peningkatan keterampilan berpikir tingkat tinggi yang diperoleh berada pada kategori sedang, namun secara kuantitatif nilainya tidak terlalu memuaskan, maka saran bagi penelitian lain untuk meningkatkan keterampilan berpikir tingkat tinggi dengan menerapkan model pembelajaran problem solving melalui bantuan alat peraga, bahan ajar, atau media interaktif seperti simulasi virtual, praktikum virtual dan laboratorium virtual untuk memudahkan penerapannya. Selain itu, penelitian metaanalisis dapat dilakukan untuk mencari artikel ilmiah dari jurnal internasional agar hasilnya lebih refrerentatif secara global.

\section{Daftar Pustaka}

Anderson, L.W., \& Krathwohl, D.R. (2010). Kerangka landasan untuk pembelajaran 
pengajaran dan asesmen. Yogyakarta: Pustaka Pelajar.

Arends, Richard, I. (1997). Classroom instruction and management, New York: McGraw-Hill.

Atqiya, N. (2016). Meningkatkan kemampuan siswa dalam mengaplikasikan rumus fisika dengan menggunakan metode problem solving dalam sintaks pengajaran langsung pada siswa kelas VIIB SMP Muhammadiyah 1 Banjar-masin. Berkala Ilmiah Pendidikan Fisika, 4(3), 237. https://doi.org/10.20527/bipf.v4i3.1003

Daryanti, S., Sakti, I., \& Hamdani, D. (2019). Pengaruh pembelajaran model problem solving berorientasi higher order thinking skills terhadap hasil belajar fisika dan kemampuan pemecahan masalah. Jurnal Kumparan Fisika, 2(2), 65-72.

Dennys, G., \& Sahya. (2013). Efek model pembelajaran problem solving dan motivasi terhadap hasil belajar fisika siswa SMA. Jurnal Pendidikan Fisika, $2(1), 65-72$.

Depdiknas. (2015). Tentang, PP No 13 tahun 2015 tentang perubahan kedua atas PP no 19 tahun 2005 standar nasional pendidikan. https://doi.org/10.1007/ s13398-014-0173-7.2.

Despaleri, P.S. (2015). Analisis pengaruh model pembelajaran berbasis masalah dengan menggunakan media flash dan sikap ilmiah terhadap kemampuan berpikir tingkat tinggi fisika siswa SMA. Jurnal Pendidikan Fisika, 4(1), 33-40.

Ernawati, E. (2016). Pengembangan perangkat pembelajaran matematika berbasis openended approach untuk mengembangkan HOTS siswa SMA. Jurnal Riset Pendidikan Matematika, 3(2), 209. https://doi.org/10.21831/jrpm.v3i2.1063.

Firmansyah. (2009). Penerapan model pembelajaran problem solving berbantuan web pada materi ekstraksi terhadap hasil belajar dan motivasi mahasiswa. Jurnal Pendidikan Sains, 39(2), 67-78.

Garrett, A.J., \& Mazzocco, M.M.M. (2006). Development of the metacognitive skills of prediction and evaluation in children with or without math disability. Learning Disabilities Research \& Practice, 21(2), 77-87.

Hadi, S. (2019). TIMSS Indonesia (Trends in international mathematics and science study). Prosiding seminar nasional \& call for papers Program Studi Magister Pendidikan Matematika Universitas Siliwangi, 562-569.

Hake, R.R. (1999). Interactive-engagement versus tradisional methods: A sixthousand-student survey of mechanics tes data for introductory physics course. American Journal of Physic, 66(1), 64-74.

I Wayana Gunanda, \& Syahrizal Ayub, K. (2019). Impementasi lesson study melalui model pembelajaran problem solving untuk meningkatkan kemampuan berpikir kreatif dan hasil belajar. Jurnal Pendidikan Fisika Dan Teknologi, 5(1), 123-133.

Jonassen, D.H. (2000). Toward a design theory of problem solving. Educational Technology Research and Development, 48(4), 63-85. https://doi.org/10.1007/ BF02300500.

Kemendikbud. (2016). Peraturan Menteri Pendidikan dan Kebudayaan Republik Indonesia Nomor 24 Tahun 2016 tentang kompetensi dasar pelajaran Pada kurikulum 2013 pada pendidikan dasar dan menengah. Jakarta: Kemendikbud.

Kusumawati A, \& Konsim, G. (2013). Pengaruh model pembelajaran partisipatif menggunakan metode pemecahan masalah terhadap hasil belajar fisika siswa kelas VIII SMPN 3 Batukliang. Jurnal Ilmiah Pendidikan Fisika, 1(2), $80-85$.

Meki, S.U. (2017). Pengaruh penggunaan metode problem solving learning terhadap hasil Belajar fisika siswa kelas XII IPA MAN 1 Pesisir Selatan. Jurnal Riset Fisika Edukasi Dan Sains, 4(1), 38-47.

Nori, A. (2019). An analysis of student's critical thinking skills In physics lesson in SMA 8 Pekanbaru. Jurnal Geliga Sains, $7(1), 11-17$.

Permana, N. D. (2018). Penerapan model pembelajaran learning cycle $7 \mathrm{E}$ berbantuan website untuk meningkatkan keterampilan berpikir kritis siswa pada materi kinematika gerak lurus. Journal of Natural Science and Integration, (1), 1141.

Rahmawati. (2013). Pengaruh model pembelajaran problem solving Terhadapa hasil belajar fisika siswa kelas VIII 
SMPN 5 Lingsar tahun pelajaran 2012/2013. Jurnal Lensa Kependidikan Fisika, 1(1).

Rahmawati, N. (2018). Pembelajaran bahasa Arab : Menuju higher order thinking skills (HOTS). Prosiding Konferensi Nasional Bahasa Arab IV, 53(9), 287. https://doi.org/10.1017/CBO9781107415 324.004

Rindayu Noviatika, \& Gunawan, J.R. (2019). Pengaruh Model pembelajaran berbasis masalah berbantuan mobile pocket book fisika terhadap kemampuan pemecahan masalah peserta didik. Jurnal Pendidikan Fisika Dan Teknologi, 5(2), 240-246.

Suherman. (2013). Meningkatkan hasil belajar siswa dengan menggunakan model pembelajaran problem solving berbasis eksperimen dalam pembelajaran fisika.
Jurnal Pendidikan Fisika, 2(2), 57-64.

Sweller, J. (1988). Cognitive load during problem solving: Effects on learning. Cognitive Science, 12(2), 257-285. https://doi.org/10.1016/0364- 0213(88)90 023-7.

Ubaidillah, M. (2016). Pengembangan LKPD fisika berbasis problem solving untuk meningkatkan keterampilan berpikir tingkat tinggi. Edufisika: Jurnal Pendidikan Fisika, 1(2), 09-20.

Werdhiana, I. K., \& Amiruddin, H. (2015). Peningkatan hasil belajar IPA fisika dengan menggunakan model pembelajaran problem solving pada siswa kelas VII SMP Negeri 18 Palu. Jurnal Pendidikan Fisika Tadalaku, 3(3), 13-17. 